\title{
JUURNAL
}

of Health Inequalities

\section{The role of the Health Promotion Foundation in building capacity to treat tobacco dependence in Poland: past, present and future}

\author{
Kinga Janik-Koncewicz ${ }^{1,2}$, Mateusz Zatoński ${ }^{1,3}$, Aleksandra Herbeć ${ }^{1,4}$, Witold A. Zatoński ${ }^{1,5}$ \\ 'Health Promotion Foundation, Nadarzyn, Poland \\ 2Doctor of Philosophy (PhD) Candidate, University of Aberdeen, UK \\ ${ }^{3}$ London School of Hygiene and Tropical Medicine, London, UK \\ ${ }^{4}$ University College London, UK \\ ${ }^{5}$ Medical University, Wrocław, Poland
}

\begin{abstract}
The Health Promotion Foundation (HPF) was established in 1991 with the goal of countering Poland's lung cancer epidemic through conducting research, building the health competence of the Polish population and organising training in smoking cessation for healthcare professionals. The HPF trained thousands of Polish doctors and nurses using as its main tool the Consensus on the Diagnosis and Treatment of Tobacco Dependence, a set of guidelines elaborated and recommended by the leading medical associations in Poland, which was distributed with support of the National Medical Chamber to each doctor in Poland. The HPF prepared a guide for smokers and healthcare providers "How to quit smoking" (Witold Zatoński) published from 1990s until now in about 1.5 million pieces. It was a sequential important element of tobacco control in Poland. At the same time, the HPF engaged in activities to increase the availability of smoking cessation drugs, and in particular disseminating the knowledge on cytisine. The HPF's work culminated in Poland becoming the first country in Eastern Europe to launch nicotine replacement therapy, in the 1990s, as well as to register and introduce bupropion on the market.

The HPF's comprehensive activities have already helped millions of Poles quit smoking. Its current work is focused on developing ways of engaging medical doctors in the treatment of tobacco dependence and the use of novel technologies in supporting effective cessation efforts, both on the side of providers and of patients. Especially, implementation of tobacco dependence treatment procedures into hospitals in Poland would be activity of special attention.
\end{abstract}

KEY WORDS: tobacco dependence treatment, smoking cessation, training for medical doctors, building capacity, Poland.

ADDRESS FOR CORRESPONDENCE: Kinga Janik-Koncewicz, Health Promotion Foundation, 51 Mszczonowska Street, 05-830 Nadarzyn, Poland, phone: +48 2237800 22, e-mail: biuro@promocjazdrowia.pl

\section{INTRODUCTION}

The Health Promotion Foundation (HPF) was established in 1991 to co-ordinate the anti-tobacco movement in Poland and implement the action points adopted in the declaration of the Conference on a Tobacco Free New Europe held in Kazimierz in November 1990 [1, 2]. Since its founding the HPF has focused on tobacco control research, advocacy, and capacity-building among healthcare professionals. The HPF led campaigns aimed at improving health awareness in Poland, conducted scientific research in health policy, epidemiology and smoking cessation, and participated in national and international scientific and implementation projects.

Although historically the anti-tobacco movement in Poland was initiated by civil society, with time it became dominated by medical doctors, scientists, oncologists, 
cardiologists, pulmonologists and others. The HPF's activities were also conducted in collaboration with the medical community, in particular with oncologists. From the very outset the HPF emphasised the importance of medicalising smoking cessation.

\section{THE HISTORY OF TOBACCO DEPENDENCE TREATMENT IN POLAND}

In 1967 Dr. Józef Granatowicz, a scientist and medical doctor working in one of the hospitals in the city of Poznań, established one of the first outpatients clinics treating tobacco dependence in the Central and East European (CEE) region. The clinic became very successful and Granatowicz soon began to conduct pioneering research on the treatment of tobacco addiction using cytisine, a plant-derived alkaloid drug developed in Bulgaria. It is an extract of the tree commonly known as "golden rain" or "golden chain" (Laburum anagyroides) from the Solanaceae family. It has a similar chemical structure and receptor binding to nicotine and is a partial agonist of cholinergic receptors in the brain. Cytisine reduces nicotine craving after quitting smoking [3].

An observational study of cytisine use for smoking cessation among 2000 patients of his clinic was described by Granatowicz in 1976 in World Smoking and Health [4]. Cytisine thus became the first evidence-based pharmaceutical product used to treat tobacco dependence in the world [5], being used in Poland and all countries of the Soviet Bloc since the mid-1970s. Its high efficacy (RR 3.4 95\% CI 1.7-7.1) and safety of have become well documented since 1970s and confirmed by modern clinical studies in the beginning of $21^{\text {st }}$ century $[6,7]$.

\section{THE LEGAL BASIS OF MODERN SMOKING CESSATION TREATMENT IN POLAND}

As a response to the high prevalence of smoking in CEE countries, the first international summit of world tobacco control leaders in the region was held in the Polish town of Kazimierz in November 1990 under the slogan "A Tobacco Free New Europe" [1, 2]. Conference delegates issued a formal statement - the so-called Kazimierz Declaration - calling on the governments of CEE countries to introduce legislative measures addressing high smoking prevalence in the region. The Declaration also urged doctors "to recognise their major responsibility in the fight against tobacco induced cancer. This should include a personal commitment not to smoke, and the provision of appropriate encouragement and advice to those wanting to quit". The Kazimierz Declaration provided a roadmap for the HPF's future activities in coordinating the Polish anti-tobacco movement and reducing the health consequences of smoking in Poland.

One of HPF's key successes was its lobbying effort to develop and introduce progressive anti-tobacco legislation in Poland. The resulting Law for the Protection of Health from the Consequences of Using Tobacco and Tobacco
Products was accepted by the Polish Parliament in 1995. It was lauded by the World Health Organisation as an "example to the rest of the world" [8]. Poland became one of the first countries in Europe to provide free treatment of tobacco dependence in healthcare settings financed from the state budget, although this did not include the cost of medicines [2]. At the end of the 1990s it was further decided that $0.5 \%$ of the tobacco excise tax was to be allocated for activities limiting tobacco consumption. More than 250 national and regional prevention and curative programmes devoted to smoking reduction were launched in Poland as a result and the social climate for tobacco control activities became one of the best in Europe [9].

Poland, represented in part by the HPF, was the country which in the name of European states led the initiative on including treatment of tobacco dependence in the Framework Convention on Tobacco Control, the first treaty ever adopted under the auspices of WHO [10]. A result of this is article 14, which requires from the signatories "support for reducing tobacco dependence and cessation, including counselling, psychological support, nicotine replacement, and education programmes" [11].

\section{CAPACITY BUILDING}

Poland has been a hub of activity in the treatment of tobacco dependence for the last 25 years. As one of the first CEE countries to do so, it provided training in smoking cessation for doctors and nurses organised jointly by the government, NGOs, and pharmaceutical companies. The first workshops for healthcare providers were prepared and conducted by HPF in the 1990s. This was continued using the train-the-trainer model by oncological, pulmonary and cardiologic institutions, as well as among psychologists, nurses and therapists. Tens of thousands of medical doctors of different specialisations and nurses have completed the training and received a certificate confirming their competence in treating tobacco dependence.

With time, the HPF has developed a comprehensive training programme tailored for different sections of the medical community. The programme proposes a scientific and empirical approach to the treatment of tobacco dependence utilising only methods of treatment which have been verified in scientific studies and recommended by independent scientific institutions (i.e. Cochrane's Library). The programme was adapted to local conditions based on the HPF's long-standing experience gained in Polish smoking cessation clinics and during population based educational campaigns. The training presents issues of tobacco dependence treatment in the context of different medical and non-medical sciences (epidemiology, toxicology, pharmacology, neurology, cardiology, pulmonology, oncology, gynaecology, neonatology, psychology, sociology). Instruction is provided by multidisciplinary teams of experts: medical doctors, psychologist, sociologist, nutritionist and other profes- 
sionals. The courses are divided into thematic modules and conducted interactively using a variety of tools and educational materials.

The basic smoking cessation resource for medical doctors in Poland - a guide on how to treat tobacco dependence - was published in 2006 [12]. This document became the basis of practitioners' knowledge of the methods, procedures, and diagnostic tools of tobacco dependence treatment. The consensus was initiated by experts from the HPF and the Maria Skłodowska-Curie Memorial Cancer Center and Institute of Oncology (CCIO) in Warsaw. Among its contributors were national consultants in cardiology, psychiatry, periodontology, gynaecology and representatives of the main medical institutions and organisations in Poland, among others the National Institute of Tuberculosis and Lung Disease, National Medical Chamber, Institute of Occupational Medicine, Polish Medical Association, and various medical academies. It was published in "Gazeta Lekarska", the periodical of the Polish Chamber of Physicians and Dentists, and distributed to medical doctors. Meanwhile, numerus medical organisations have prepared additionally some specific guidelines. For example, in 2011 a statement on the diagnosis and treatment of tobacco dependence among patients with cardiovascular disease was published within one of the projects conducted by the HPF and devoted to training for healthcare providers [13].

In 2009 the HPF initiated a special project entitled "Smoking is treatable". Conducted within the Global Health Partnership Program, this project aimed to increase knowledge among healthcare professionals about tobacco dependence treatment. Training modules were developed on the treatment of tobacco dependence for medical students and physicians (general practitioners and specialists: cardiologists and pulmonologists). The training was based on the Polish Consensus on Diagnosis and Treatment of Tobacco Dependence. Each module targeted a different group of health professionals and provided participants with information on cessation methods and characteristics of tobacco dependence diagnosis and treatment methods, but also enhanced their motivation to start treating patients suffering from tobacco dependence. Alongside medical doctors, medical students were the second target group trained within the project. Non-obligatory lectures on the diagnosis and treatment of tobacco dependence were provided for students at the Medical University in Wrockaw. These workshops met with great interest among students. However, results from a survey conducted among students indicated that their knowledge of smoking cessation and pharmaceutical treatment is low, suggesting intensive compulsory educational activities could be beneficial [14].

Nurses, especially those having personal contact with patients in clinics and hospitals, are another group of healthcare providers who can support the process of quitting smoking. The participation of nurses in the treatment of tobacco dependence requires educational activities, implementation of basic diagnostic and therapeutic procedures, and their positive attitudes towards the integration of smoking cessation treatment into their duties. One of the programmes devoted to engaging nurses in cessation efforts in recent years was Eastern Europe - Helping Smokers Quit (EE-HSQ), led by the International Society of Nurses in Cancer Care and the University of California. The project was implemented in Poland, the Czech Republic, the USA and China as part of the programme Bridging Cancer Care, financed by the Bristol-Myers Squibb Foundation. In Poland it was conducted in collaboration with the National Chamber of Nurses and Midwives, HPF, and the Institute of Oncology in Warsaw. One of the conclusions of the project was that tobacco control and cessation education activities for nurses are crucial to obtaining a decrease in the rates of tobacco-related diseases. One of the most accessible and scalable methods of providing instruction to a large number of nurses would be through online courses [15].

In addition to its activities in Poland, the HPF was also engaged in efforts to build capacity in tobacco control and smoking cessation in other CEE countries. In the years 2007-2009 HPF conducted the TICI project ("Toward closing the gap in tobacco control and health burden between Eastern and Western Europe") within the Bloomberg Initiative to Reduce Tobacco Use, supporting the development of evidence-based tobacco control policies and programmes in Poland and other CEE countries. The project comprised three separate work packages, drawn together during a regional summit assessing progress, identifying challenges, and agreeing a way forward. Crucially, the project used the expertise and commitment of health professionals, as well as their associations, to provide leadership on tobacco control in the CEE region. Using its experience in capacity-building for treatment of tobacco dependence, the HPF organised a series of workshops and consultations, and produced educational materials and tools for medical doctors and nurses in Kazakhstan and Kyrgyzstan.

During 26 years of work, HPF has been building network of scientists, researchers, experts in different medical specialisations in Poland and other countries, who supported its activities. Treatment of tobacco dependence was one of the main themes of the conferences that were organised in Poland, i.e. annual National Scientific Conference "Tobacco or health". Experts collaborating with HPF have contributed to international conferences showing Polish achievements, experience and results from numerous projects oriented on smoking cessation conducted by the HPF.

"Crewe programme" was a project corresponding with practical activities in range of smoking cessation programme for Polish migrants in England. The programme was conducted in collaboration with Smoke 
Free North West and the Central and Eastern Cheshire PCT and Jon Dawson Associates. It was piloted in demonstration site in community of Crewe in 20082009. The aim of the programme was to build capacity for changing the attitudes toward smoking and increasing quit smoking rates among Polish migrants, especially pregnant women. Considering transferable lessons from Poland's research and tobacco dependence treatment experience, the programme tried to identify the patterns of smoking behaviours among Polish migrants, find out psychological, socio-economic and cultural barriers they meet when stopping smoking, provide a community adapted model and tools for stop smoking support, and provide more effective stop smoking services in community based settings for Polish migrants. The Health Promotion Foundation conducted a community-based survey on smoking behaviours and attitudes toward stopping smoking and tobacco control policy, organized focus groups for different potential quitters, trained stop smoking cessation staff in Crewe, designed a strategy for building more effective stop smoking service, and prepared and provided leaflets, guideline and other health education materials for Polish migrants.

PESCE project was coordinated by EU and it's general objective was to motivate increased smoking cessation interventions of General Practitioners (GP) in Europe by addressing the socio-economic environment of GP's practice, analyse long term health benefits and economic growth brought about by increased smoking cessation interventions by GP's, taking into account the effects on the health sector and the improvement of productivity and economic conditions of citizens in general. The specific objective was to develop evidence based policy recommendations and implementation strategies to change the socio-economic environment through political measures to motivate greater involvement of GP's in smoking cessation interventions. A multi-country literature review done within the project showed that most doctors in Europe have asked their new patients on smoking status, but few advised smokers to quit, and the proportion of doctors offering intensive interventions (including medicines) to stop smoking has been low [16].

\section{DEVELOPMENT OF CESSATION SUPPORT}

In the 1990s, Poland established a network of smoking cessation clinics. The clinics offered help to smokers trying to quit, through counselling, psychological and behavioural support, as well as pharmacological treatment. The first smoking cessation clinic was established by the HPF at the CCIO in Warsaw. It was a reference clinic providing complex care in the treatment of tobacco dependence, including educational activities, diagnosis (with a focus on assessing exposure, dependence, motivation and readiness to quit), behavioural support aimed at inducing and maintaining the motivation to quit, medical treatment, follow-up visits, and sustained contact with patients. In addition to this work, the clinic also conducted research activities. Only evidence-based methods and procedures were included in clinic's routine.

The basic educational material for smokers wanting to quit used in Poland since the 1990s was the "How to quit smoking" brochure written by Witold Zatoński [17]. It is a compendium of knowledge on tobacco addiction, the drivers of tobacco smoking, advice on the run-up period of quitting, methods used to quit, support and practical tips on how to persevere in abstinence. The brochure included a self-control guide including tests to determine an individual's preparedness and level of motivation to quit, as well as the strength of tobacco dependence. It was published in multiple editions and printed in millions of copies (see Fig. 1).

Further smoking cessation support in Poland has been provided by a national telephone quitline, based at the CCIO in Warsaw since 1996, when it was launched by the HPF. It was the first quitline in CEE and one of only a few in the European region. The service offers support to smokers who want to quit as well as quitters who need support in maintaining abstinence. Quitline counsellors follow international guidelines and provide evidence-based smoking cessation advice.

\section{SMOKING CESSATION DRUGS}

Lobbying for better availability of smoking cessation drugs in Poland has been a particularly successful effort of the HPF. In the 1980s and 1990s HPF promoted wide access to nicotine replacement therapy, first available in "Pewex", a chain of hard currency shops in communist Poland. Since 2001 the HPF has participated in the introduction of "Zyban" (the brand name of bupropion-based medicine, which is antidepressant, a nicotinic antagonist which reduces the severity of nicotine cravings and withdrawal symptoms) to the market, making Poland the first CEE country to register this drug. Most significantly, Poland became a hub for the development and distribution of cytisine. In the year 2000 the HPF and the CCIO in Warsaw began preparing full medical documentation for this drug, used in Poland and other CEE countries for decades to treat tobacco dependence. This work was born out of the conviction that cytisine had an important role in driving down the smoking rates in Poland and the prevention of CVD, pulmonary diseases and cancer. It culminated in a series of publications on the history and role of cytisine $[3,18]$. Witold Zatoński initiated the first study in a long time to assess the effectiveness and safety of cytisine [6]. Simultaneously, at the end of 2005, the first randomised controlled double-blind study on the effectiveness of cytisine was carried out in Poland, under the guidance of Prof. Zatoński and the CCIO and in collaboration with the team of Prof. Robert West from the Cancer Research UK Health Behaviour Research Centre in University College London. Results of the study, confirming the effectiveness and safety of cytisine in the 


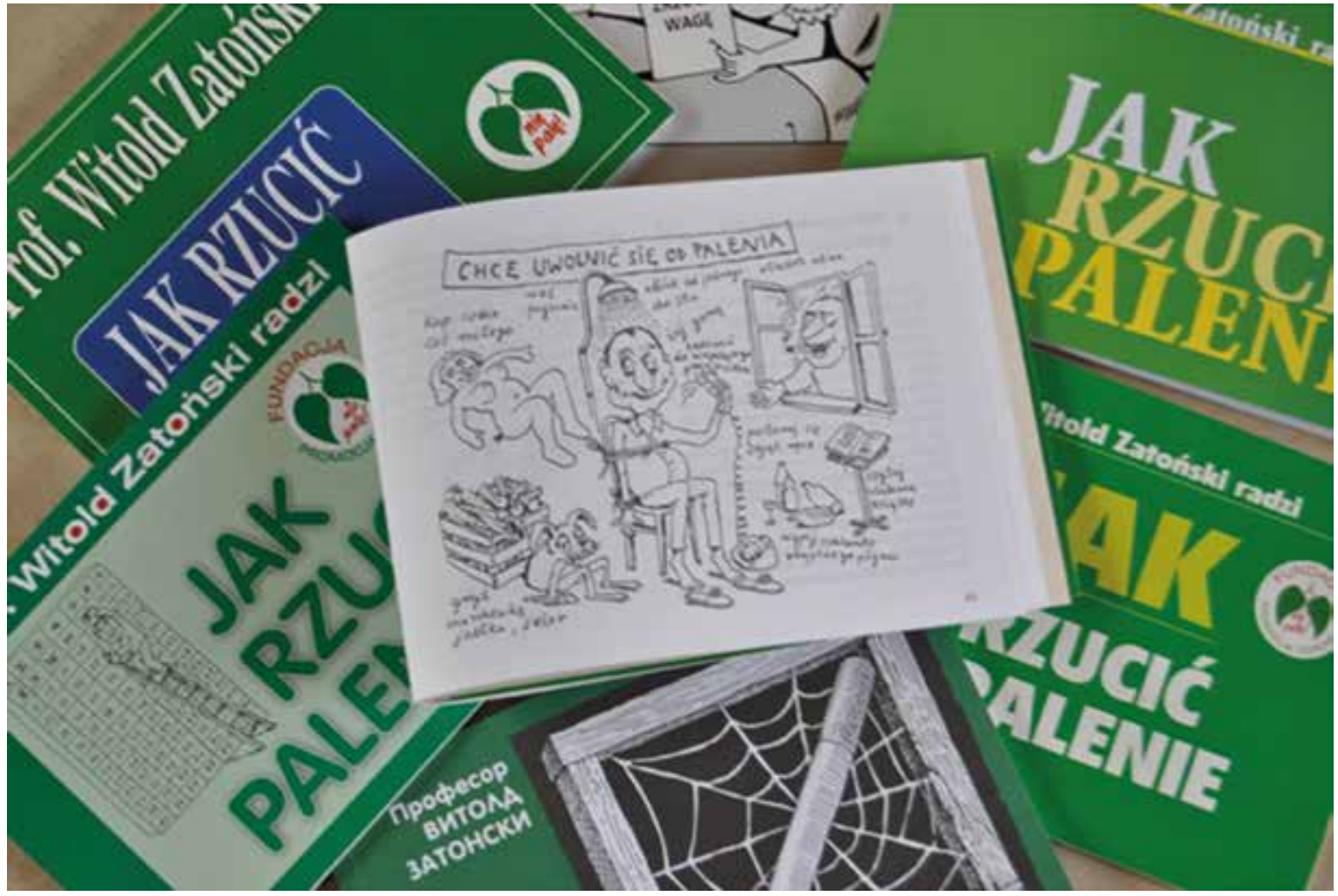

FIG. 1. Exemplary editions of the brochure "How to quit smoking"

treatment of tobacco dependence, were published in the New England Journal of Medicine [19]. This paper met with huge interest in the scientific world and had substantial influence on the growth of availability and popularity of cytisine in Poland in recent years. Subsequent studies in other countries have further demonstrated the effectiveness of cytisine, including in comparison to nicotine replacement therapy [7].

As HPF's research became widely disseminated, cytisine began to be used more frequently to treat tobacco dependence in Poland. The regulatory authority allowed it to be advertised and sold without a prescription. In addition to the cytisine brand "Tabex", produced by the Bulgarian company "Sopharma”, from 2013 a Polish company began to sell cytisine under the brand name "Desmoxan". A very intensive advertising campaign was launched for the new product on radio and television. As a result the sale of cytisine in Poland increased sharply [20]. In recent years (including 2016) annual sales of cytisine reached around 1 million packages. Poland is currently the only country in the world where $90 \%$ of cessation aid medicines consist of partial nicotine agonist drugs such as cytisine, rather than nicotine replacement therapy. Every year $12.5 \%$ of smokers (one million out of eight million current smokers) make a quit attempt using cytisine [21].

\section{THE FUTURE}

Despite the HPF's 26 years of research, lobbying, training, networking and capacity building, much remains to be done in the field of smoking cessation in Poland. The treatment of tobacco dependence is still not a routine procedure conducted by health care providers [16]. For this reason the HPF's new projects emphasise the development of new methods and the use of technology to engage and support health professionals in providing smoking cessation advice as part of their regular routine. HPF has just launched a new programme with the goal of developing a platform which will act as a support tool and expert system for training, delivery of evidence-based treatment, data gathering, and networking, for healthcare professionals offering cessation treatment. The project is conducted in collaboration with the UCL Tobacco and Alcohol Research Group and the National Centre for Smoking Cessation and Training in the UK, and funded within Global Bridges at Mayo Clinic and Pfizer Independent Grants for Learning and Change [22].

\section{CONCLUSIONS}

Treatment of tobacco dependence is listed by the FCTC as a key component of a comprehensive strategy to counteract the tobacco smoking epidemic [23]. There are a number of basic activities focusing on smoking cessation. The most important are: introduction of tobacco dependence treatment into curricula of medical academies and into the daily routine of medical doctors, creating a national network of cessation clinics, facilitating access to drugs used in smoking cessation and population-based programmes, and campaigns aimed 
at changing behaviours and attitudes towards smoking and at motivating people who wish to quit. The HPF has made numerous attempts to implement the abovementioned activities in Poland.

However, to achieve continued, sustainable smoking cessation rates, especially among highly addicted smokers, an equally important element is the engagement of the medical community in the treatment process. Medical counselling, also from cultural point of view in Poland, can be one of the most motivating cessation activities. General practitioners, but also specialists (cardiologists, pulmonologists, oncologists, paediatricians and others) must become aware that tobacco dependence treatment is an obligation for the medical profession. It will be one of the HPF's key priorities in the next years to develop this awareness and build a set of tools assisting clinicians in helping smokers to successfully quit. The special attention will be put on inclusion elements of diagnosis and treatment of tobacco dependence into hospital procedures. Special area of interest is introduction of innovative telemedicine technology. It seems especially important in time of tobacco endgame, when most of smokers have been deeply nicotine-addicted, declared willingness to quit and undertaken many quit attempts without results.

\section{ACKNOWLEDGEMENTS}

Authors would like to acknowledge the invaluable assistance of Mr. Scott Thompson in the preparation of the final version of this article.

\section{DISCLOSURE}

Authors report no conflicts of interest.

\section{References}

1. Zatoński M, Zatoński WA, Przewoźniak K, et al. The significance and impact of the Polish Anti-tobacco Law. J Health Inequal 2016; 2: 32-35.

2. Zatoński W. Democracy is healthier. A Nation's Recovery. Tobacco control in Poland. Health Promotion Foundation, Warsaw 2003.

3. Tutka P, Zatoński W. Cytisine for the treatment of nicotine addiction: from a molecule to therapeutic efficacy. Pharmacol Rep 2006; 58: 777-798.

4. Granatowicz J. Smoking cessation through the use of cytisine and other chemotherapy. World Smoking Health 1976; 1: 8-11.

5. Prochaska JJ, Das S, Benowitz NL. Cytisine, the world's oldest smoking cessation aid. BMJ 2013; 347: f5198.

6. Zatoński W, Cedzyńska M, et al. An uncontrolled trial of cytisine (Tabex) for smoking cessation. Tob Control 2006; 15: 481-484.

7. Walker N, Howe C, Glover M, et al. Cytisine versus nicotine for smoking cessation. New Engl J Med 2014; 371: 2353-2362.

8. Blanke DD, de Costa e Silva V. Tools for advancing tobacco control in the $21^{\text {st }}$ century. Tobacco Control legislation: An introductory guide. World Health Organization, Geneva 2004.

9. Fagerström K, Boyle P, Kunze M, Zatoński W. The anti-smoking climate in EU countries and Poland. Lung Cancer 2001; 32: 1-5.
10. Roemer R, Taylor A, Lariviere J. Origins of the WHO Framework Convention on Tobacco Control. Am J Public Health 2005; 95: 936-938.

11. Note from the Editors. The WHO Framework Convention on Tobacco Control (FCTC). J Health Inequal 2016; 2: 129.

12. Zatoński W (ed.). Konsensus dotyczący rozpoznawania i leczenia zespołu uzależnienia od tytoniu [Consensus on diagnosis and treatment of tobacco dependence]. Med Prakt 2006; 7 (special ed.): 5-24.

13. Zatoński W, Jankowski P, Banasiak W, et al. Wspólne stanowisko dotyczące rozpoznawania i leczenia zespołu uzależnienia od tytoniu u pacjentów z chorobami układu sercowo-naczyniowego [Common position on diagnosis and treatment of tobacco dependence among CVD patients]. Kardiol Pol 2011; 69: 96-100.

14. Janik-Koncewicz K, Zatoński T, Połtyn-Zaradna K, et al. An attempt to assess knowledge about tobacco dependence among students at the Medical University in Wroclaw. Ann Agr Environ Med 2012; 19: 345-349.

15. Bialous SA, Sarna L, Wells MJ, et al. Impact of online education on nurses' delivery of smoking cessation interventions with implications for evidence-based practice. Worldviews Evid Based Nurs 2017; 14: 367-376.

16. Stead M, Angus K, Holme I, et al.; PESCE European Research Team. Factors influencing European GPs' engagement in smoking cessation: a multi-country literature review. Br J Gen Pract 2009; 59: 682-690.

17. Zatoński W. Jak rzucić palenie. Profesor Witold Zatoński radzi [How to quit smoking. Professor Witold Zatoński advises]. Medycyna Praktyczna, Kraków 2007.

18. Tutka $P, Z$ atoński W. Cytyzyna. Właściwości farmakologiczne leku stosowanego w leczeniu zespołu uzależnienia od tytoniu [Cytisine. Pharmacological characteristics of drug used in treatment of tobacco dependence]. Medycyna Praktyczna, Kraków 2005.

19. West R, Zatoński W, et al. Placebo-controlled trial of cytisine for smoking cessation. New Engl J Med 2011; 365: 1193-1200.

20. Zatoński W, Zatoński M. Cytisine versus nicotine for smoking cessation. New Engl J Med 2015; 372: 1072.

21. Data from International Tobacco Control survey in Poland.

22. Herbeć A, Janik-Koncewicz K, McEwan A, et al. Development and evaluation of STAR - an expert digital platform supporting training and delivery of cessation intervention by healthcare professionals in Poland. Project Overview. J Health Inequal 2017; 2: 133-137.

23. World Health Organization. WHO Framework Convention on Tobacco Control. World Health Organization, Geneva, 2003. Polish text of the Convention available in Dz.U. Nr 74/2006, poz. 487.

\section{AUTHORS' CONTRIBUTIONS}

KJK wrote the article. AH prepared the project concept and drafted the publication. KJK contributed to article revision and edits. WAZ, AM and RW consulted on STAR project. All authors approved the final version of the article. 